\title{
Replacement time of mining drilling rigs
}

\author{
Hussan Hamodi ${ }^{1}$; Jan Lundberg ${ }^{2}$ \\ ${ }^{1}$ hussan.hamodi@ltu.se; ${ }^{2}$ Jan.Lundberg@ltu.se \\ 1,2 Division of Operation, Maintenance and Acoustics - Luleå University of Technology \\ Luleå, Sweden
}

\begin{abstract}
This paper presents a practical model to calculate the optimal replacement time (ORT) of drilling rigs used in underground mining. As a case study, cost data for drilling rig were collected over four years from a Swedish mine. The cost data include acquisition, operating, maintenance and downtime costs when using a redundant rig. A discount rate is used to determine the value of these costs over time. The study develops an optimisation model to identify the ORT of a mining drilling rig which represents a key performance indicator. It uses an artificial neural network (ANN) technique to identify the effect of the various cost factors on the ORT. The absolute ORT in the case study is 87 months, and there is an optimal replacement range within which the company can replace the rig. The results also show that the redundant rig cost has the largest impact on the ORT followed by acquisition, maintenance and operating costs. Regression analysis shows a linear relationship between the cost factors and the ORT of the drilling rig.
\end{abstract}

Keywords: capital equipment, decision support models, life cycle cost, optimal replacement time, optimisation model.

\begin{tabular}{|c|c|c|c|}
\hline \multicolumn{4}{|c|}{ Abbreviations } \\
\hline ORT & $\begin{array}{l}\text { Optimal replacement } \\
\text { time (month) }\end{array}$ & $P_{T_{i}}$ & $\begin{array}{l}\text { Using time of redundant } \\
\text { rig (h) }\end{array}$ \\
\hline ANN & $\begin{array}{l}\text { Artificial neural } \\
\text { network }\end{array}$ & $C_{R_{i}}$ & $\begin{array}{l}\text { Redundant rig cost per } \\
\text { hour (cu/h) }\end{array}$ \\
\hline TC & Total cost (cu) & $T_{R_{i}}$ & $\begin{array}{l}\text { Logistic time for redundant } \\
\text { rig (h) }\end{array}$ \\
\hline $\mathrm{cu}$ & Currency unit & $T_{F_{i}}$ & $\begin{array}{l}\text { Restoring time of the faulty } \\
\text { rig to operation (h) }\end{array}$ \\
\hline$A C$ & Acquisition cost (cu) & $T_{1 i}$ & $\begin{array}{l}\text { Moving time of redundant } \\
\text { rig from its location to } \\
\text { production point (h) }\end{array}$ \\
\hline$i$ & Time period (month) & $T_{2 i}$ & $\begin{array}{l}\text { Moving time of redundant } \\
\text { rig from production point } \\
\text { to its original location (h) }\end{array}$ \\
\hline$R T$ & $\begin{array}{l}\text { Replacement time } \\
\text { (month) }\end{array}$ & $T_{M_{i}}$ & $\begin{array}{l}\text { Moving time of faulty rig } \\
\text { from production point to } \\
\text { workshop (h) }\end{array}$ \\
\hline$M C_{i}$ & Maintenance cost (cu) & $T_{W_{i}}$ & $\begin{array}{l}\text { Time in workshop of faulty } \\
\text { rig (h) }\end{array}$ \\
\hline$O C_{i}$ & Operating cost (cu) & $T_{L_{i}}$ & $\begin{array}{l}\text { Moving time of repaired } \\
\text { rig from workshop to } \\
\text { production point (h) }\end{array}$ \\
\hline $\mathrm{CO}_{i}$ & $\begin{array}{l}\text { Compensation cost } \\
\text { (cu) }\end{array}$ & $t_{d_{i}}$ & $\begin{array}{l}\text { Delay time in workshop of } \\
\text { faulty rig before repair (h) }\end{array}$ \\
\hline$S_{i}$ & Resale value (cu) & $t_{r_{i}}$ & $\begin{array}{l}\text { Actual repair time of faulty } \\
\text { rig (h) }\end{array}$ \\
\hline & Discount rate (\%) & $t_{I_{i}}$ & $\begin{array}{l}\text { Idle time in workshop of } \\
\text { faulty rig after repair (h) }\end{array}$ \\
\hline$T$ & $\begin{array}{l}\text { Planned life time } \\
\text { (month) }\end{array}$ & $B V_{1}$ & $\begin{array}{l}\text { Rig value at the first day of } \\
\text { operation (cu) }\end{array}$ \\
\hline
\end{tabular}

$\begin{array}{llll}C M_{i} & \begin{array}{l}\text { Corrective } \\ \text { maintenance cost (cu) }\end{array} & \text { Dr } & \begin{array}{l}\text { Depreciation rate } \\ P M_{i}\end{array} \\ \begin{array}{l}\text { Preventive } \\ \text { maintenance cost (cu) }\end{array} & S V & \text { Scrap value (cu) } \\ S P_{C i} & \begin{array}{l}\text { Spare part cost for } \\ \text { corrective } \\ \text { maintenance (cu) }\end{array} & \text { IAC } & \begin{array}{l}\text { Increasing acquisition cost } \\ (\%)\end{array} \\ L C_{C i} & \begin{array}{l}\text { Labour cost for } \\ \text { corrective } \\ \text { maintenance (cu) }\end{array} & R M C & \begin{array}{l}\text { Reduced maintenance cost } \\ (\%)\end{array} \\ S P_{P_{i}} & \begin{array}{l}\text { Spare part cost for } \\ \text { preventive }\end{array} & R O C & \begin{array}{l}\text { Reduced operating cost } \\ \text { maintenance (cu) }\end{array} \\ L C_{P i} & \begin{array}{l}\text { Labour cost for } \\ \text { preventive } \\ \text { maintenance (cu) } \\ \text { Redundant rig cost } \\ \text { (cu) }\end{array} & \text { h } & \begin{array}{l}\text { Reduced redundant rig cost } \\ (\%)\end{array} \\ R C_{i} & \text { Hour }\end{array}$

\section{INTRODUCTION}

Mines are important sources of minerals and energy resources. An extremely important and very expensive piece of equipment used in mineral extraction is a drilling rig. Drilling rigs are necessary for production, but like all equipment used in underground mining, they are subject to degradation throughout their operating life. Therefore, the operating cost increases as a result of increased operating hours, causing a negative economic effect. In addition, the equipment used in underground mining is subject to a harsh working environment, and this accelerates its degradation. Given all these factors, a key question for mining companies is when to replace equipment to minimise cost. The optimum replacement age of equipment is defined as the time at which the total cost is at its minimum value [1]. In this study, total cost is represented by investment (acquisition or initial), operating and maintenance costs, and compensation cost.

Bellman [2] developed the first optimal asset replacement model for the variable lifetime of assets. Wagner [3] offered dynamic programming formulation for the equipment replacement problem in which the state of the system is the time period and the decision in each replacement is to keep the equipment for $N$ periods. His formulation has been extended by researchers to deal with technological changes [4-7]. These researchers assume a finite horizon in their approach to the problem of equipment replacement under non-stationary costs. A number of researchers have studied the ORT of capital equipment. Some use the theory of dynamic programming considering technological changes under finite and infinite horizons [5; 8; and 9]. Others consider the optimal lifetime of 
capital equipment using economic theories and vintage capital models, represented mathematically by non-linear Volterra integral equations with unknown limits of integration [10-13]. Hartman and Murphy [14] offer a dynamic programming approach to the finite horizon equipment replacement problem with stationary cost. Their model studies the relationship between the infinite horizon solution and the finite-horizon solution. Kärri [15] considers the optimal replacement time of an old machine, using an optimisation model which minimises the machine cost. The model is built to handle capacity expansion and replacement situations using real costs without inflation. Hritonenko and Yatsenko [16] construct a computational algorithm to solve a nonlinear integral equation; the solution is important for finding the optimal policy of equipment replacement under technological advances. Other researchers have considered reliability, maintainability and optimum replacement decisions; readers are referred to, e.g., [17; 18] for further information.

Blanchard et al. [19] mention that the costs associated with equipment operation and maintenance can account for more than $75 \%$ of the equipment life cycle cost. Given the importance of operation, maintenance and loss of production costs, industries often use redundant production equipment to prevent loss of production. Another solution is to make a pooling agreement with other companies, whereby they rent a piece of equipment to ensure the failed equipment will be replaced by a serviceable machine. But any of these compensation strategies cost money. Thus, the aim of this paper is to present a practical model for to determine the optimal replacement time of capital equipment, considering the redundant rig cost. The paper also examines the relative importance of the most influential cost factors on the ORT of a drilling rig: acquisition, operating, maintenance and redundant rig costs. Finally, the optimisation model considers the time value of money by using a discount rate.

\section{CASE STUDY AND DATA COLLECTION}

The study tests the ORT model on a case study of equipment used in the mining industry. A typical mining cycle can be represented by the following processes; drilling, charging, blasting, loading, scaling and bolting. Because drilling is the first step in the cycle and the drilling rig has high acquisition and maintenance costs, the drilling rig is selected as a case study. The drilling rigs used in mines are manufactured by different companies and have different technical characteristics, e.g. power and capacity, but all are composed of similar operating units, including cabin, boom, rock drill, hose reeling unit, hydraulic pump, front jacks, feeder, rear jack, electric cabinet, service platform, cable reeling unit, diesel engine, operator panel, oil reservoir and water tank. The cost data in the mine used in this study were collected over four years in the MAXIMO computerised maintenance management system (CMMS). The cost data contain preventive maintenance costs, corrective maintenance costs, and repair time. The preventive and corrective maintenance costs contain labour and spare parts costs. In CMMS, the cost data are recorded based on calendar time. Since drilling is not a continuous process, the operating cost is estimated by considering the utilisation of the rig. The operating costs are administration, fuel, energy, operator's salary, consumables like steel rods, indirect overhead costs, etc. Due to the regulations of the collaborating mining company, all cost data are encoded and expressed as currency units (cu).

\section{MODEL DEVELOPMENT}

The ORT of capital equipment is the age that minimises total cost. In this study, the total cost is represented by investment (acquisition or initial) costs, operating and maintenance costs, and compensation costs. All repairable equipment wears with age, leading to increasing operating and maintenance $(O \& M)$ costs (data collected from MAXIMO in our case study), and decreasing resale value. This study examines the ORT problem over a finite time horizon. The engineers at the collaborating mining company say the company plans to use a drilling rig for ten years (i.e. 120 months). The objective of the optimisation model is to minimise the discounted total cost over this period. In this paper, the ORT of drilling rig is defined as the value of the replacement time $(R T)$ which minimises the total cost, as shown in the following model:

$$
T C=\left[\left\{\begin{array}{l}
\left(A C+\left[\sum_{i=1}^{R T}\left(M C_{i}+O C_{i}+C O_{i}\right)\right]-S_{i}\right) \\
\times \frac{1}{(1+r)^{\frac{i}{12}}}
\end{array}\right\} \times \frac{T}{R T}\right](1)
$$

where TC, $A C, M C_{i}, O C_{i}, C O_{i}, S_{i}, r, T$ represent the total cost, acquisition cost, maintenance cost, operating cost, compensation cost, resale value, discount rate and planned lifetime respectively.

We assume the replacement rig (i.e. anew rig) has the same performance as the existing rig (i.e. identical rigs). The number of replacement cycles during the planned lifetime is equal to the planned lifetime divided by the replacement time. The maintenance cost is a summation of materials and labour expenses required to keep the equipment in suitable working condition. In this paper, the maintenance cost is represented as follows:

$$
M C_{i}=C M_{i}+P M_{i}
$$

where $C M$ and $P M$ represent corrective and preventive maintenance cost (cu) respectively.

$$
C M_{i}=S P_{C_{i}}+L C_{C_{i}}
$$

where $S P_{C_{i}}$ and $L C_{C}$ represent spare part costs and labour costs for corrective maintenance $(\mathrm{cu})$ respectively.

$$
P M_{i}=S P_{P_{i}}+L C_{P_{i}}
$$

where $S P_{P_{i}}$ and $L C_{P_{i}}$ represents spare part costs and labour costs for preventive maintenance (cu) respectively.

In this study we focus on the redundant rig cost as a critical factor affecting the ORT of a drilling rig. The maintenance 
experts at the collaborating mine classify rig failures in three categories as follows:

1. Failures fixed by maintenance team at the workshop.

2. Failures fixed by maintenance team at the production point.

3. Failures fixed by operators at the production point.

Note: we obtained information on the drilling process and maintenance of drilling rigs after discussions with experts in the user company (U) and manufacturing company (M). Detailed information, such as experience in years and work position of the experts, is provided in Table I.

TABLE I. DESCRIPTION OF EXPERTISE OF THE EXPERT GROUP

\begin{tabular}{|l|l|}
\hline \multicolumn{1}{|c|}{$\begin{array}{c}\text { Current position at } \\
\text { companies (U) and (M) }\end{array}$} & \multicolumn{1}{|c|}{$\begin{array}{c}\text { Expert field and experience (\# } \\
\text { years) }\end{array}$} \\
\hline $\begin{array}{l}\text { Maintenance Engineer } \\
\text { (U) }\end{array}$ & $\begin{array}{l}\text { Maintenance of mobile and fixed } \\
\text { equipment's (23) }\end{array}$ \\
\hline $\begin{array}{l}\text { Mine production } \\
\text { Foreman (U) }\end{array}$ & Underground drill machines (30) \\
\hline $\begin{array}{l}\text { Mine production } \\
\text { Manager (U) }\end{array}$ & Mine drilling and production (15) \\
\hline $\begin{array}{l}\text { Mine production } \\
\text { Planner (U) }\end{array}$ & Mine production planning (22) \\
\hline $\begin{array}{l}\text { Maintenance Supervisor } \\
\text { (U) }\end{array}$ & $\begin{array}{l}\text { Maintenance of mobile equipment's } \\
\text { (30) }\end{array}$ \\
\hline $\begin{array}{l}\text { Maintenance Manager } \\
\text { (U) }\end{array}$ & $\begin{array}{l}\text { Maintenance of mobile equipment's } \\
(26)\end{array}$ \\
\hline $\begin{array}{l}\text { Mine production } \\
\text { Manager (U) }\end{array}$ & Mine drilling and production (32) \\
\hline $\begin{array}{l}\text { Maintenance Foreman } \\
\text { (U) }\end{array}$ & $\begin{array}{l}\text { Maintenance of mobile equipment's } \\
(25)\end{array}$ \\
\hline $\begin{array}{l}\text { Maintenance Engineer } \\
\text { for fixed equipment (U) }\end{array}$ & $\begin{array}{l}\text { Maintenance of fixed equipment's } \\
(10)\end{array}$ \\
\hline $\begin{array}{l}\text { Global Service } \\
\text { Operations Manager } \\
\text { (M) }\end{array}$ & Maintenance of equipment (20) \\
\hline $\begin{array}{l}\text { Design Engineer- } \\
\text { Underground Drill Rigs } \\
\text { (M) }\end{array}$ & $\begin{array}{l}\text { Designing underground equipment } \\
\text { (10) }\end{array}$ \\
\hline $\begin{array}{l}\text { Global Fleet Manager } \\
\text { Europe and product line } \\
\text { manager-Rental (M) }\end{array}$ & $\begin{array}{l}\text { Marketing and business management } \\
(8)\end{array}$ \\
\hline $\begin{array}{l}\text { Operations (M) } \\
\text { management (10) }\end{array}$ \\
\hline $\begin{array}{l}\text { Parts and Service Business } \\
\text { management and Maintenance of } \\
\text { mobile equipment (18) }\end{array}$ \\
\hline
\end{tabular}

\section{A. First category of failures}

In the first category, failures are fixed by the maintenance team at the workshop. In this study, we assume if a rig fails and must be sent to the workshop for maintenance, the company will use a redundant rig which has the same performance as the faulty rig. Since in the mining industry, the downtime in production is almost zero, the compensation cost in this case represents the cost of using the redundant rig. As the drilling rig has failed, the drilling process will stop. The redundant rig must move from its location to the production point; the drilling process will be restarted with the redundant rig. The faulty rig must move from the production point to the workshop for repair. After repair, the faulty rig will return to the production point; the drilling process will continue by using the repaired drilling rig. The redundant rig will move from the production point back to its original location. Therefore, the compensation cost based on the first category of failures is modelled as follows:

$$
C O_{i}=R C_{i}=P_{T_{i}} \times C_{R_{i}}
$$

where $C O_{i}$ represents the compensation cost (cu), $R C_{i}$ represents the redundant rig cost (cu), $P_{T_{i}}$ represents the using time of the redundant rig (h) and $C_{R_{R}}$ represents the redundant rig cost per hour, in this case study, 3 (cu/h).

$$
P_{T_{i}}=T_{R_{i}}+T_{F_{i}}
$$

where $T_{R_{i}}$ represents the logistic time for a redundant rig (h) and $T_{F_{i}}$ represents the time taken to restore the faulty rig to operation (h).

$$
T_{R_{i}}=T_{1_{i}}+T_{2_{i}}
$$

where $T_{1_{i}}$ and $T_{2_{i}}$ represent the time to move the redundant rig from its location to the production point and the return time after finishing its job from the production point to its original location (h) respectively.

$$
T_{F_{i}}=T_{M_{i}}+T_{W_{i}}+T_{L_{i}}
$$

where $T_{M_{i}}, T_{W_{i}}$ and $T_{L_{i}}$ represent the time to move a faulty rig from the production point to the workshop (h), time in workshop (h) and the moving time for the repaired rig from the workshop to the production point (h) respectively.

$$
T_{W_{i}}=t_{d_{i}}+t_{r_{i}}+t_{I_{i}}
$$

where $t_{d_{i}}$, $t_{r_{i}}$ and $t_{I_{i}}$ represent delay time in the workshop before repair (h), actual repair time (h) and idle time in the workshop after repair (h) respectively.

\section{B. Second category of failures}

This category includes the failures fixed by the maintenance team at the production point (mining room). Suppose a rig is stopped and can be repaired in its location (i.e. production point). We assume the company will use a redundant rig with the same performance as the faulty rig. The compensation cost in this case represents the cost of using a redundant rig. As the drilling rig has failed, the drilling process will stop. The redundant rig must move from its location to the production point; the drilling process will be restarted using the redundant rig. The maintenance team will move from the workshop to the production point to repair the faulty rig. After repair, the drilling process will continue with the repaired drilling rig. The redundant rig will start to move from the production point back to its original location. Therefore, in the second category of failures, the usage time of the redundant rig when a fault is found in the existing rig is modelled as follows:

$$
P_{T_{i}}=T_{M_{i}}+T_{R_{i}}+t_{r_{i}}
$$


Since the moving speed inside the underground mine is limited to low speed, we assume the moving time of the maintenance team from the workshop to the production point is almost equal to the moving time of the faulty rig from the production point to the same workshop. Table II illustrates the minimum and maximum time values used in the model, following the suggestions of the maintenance expert in the collaborating mine.

TABLE II. MINIMUM AND MAXIMUM TIME VALUES (HOUR) USED IN THE MODEL

\begin{tabular}{|l|l|l|}
\hline \multicolumn{1}{|c|}{ Description } & Minimum & Maximum \\
\hline $\begin{array}{l}\text { Moving time for faulty rig from } \\
\text { production point to workshop }\end{array}$ & 0.5 & 1 \\
\hline Delay time in workshop before repair & 0.5 & 1.5 \\
\hline Idle time in workshop after repair & 0.5 & 1 \\
\hline
\end{tabular}

The time values $t_{d_{i}}, t_{I_{i}}, T_{M_{i}}, T_{L_{i}}, T_{1_{i}}$ and $T_{2_{i}}$ are simulated by using MATLAB code for the use of the redundant rig over four years, since this type of data is not available from the collaborating mine. We assume the moving times of the redundant rig $T_{1_{i}}$ and $T_{2_{i}}$ are equal to the moving time of the faulty rig $T_{M_{i}}$. We use a discount rate of $10 \%$ to consider the time value of money, again following the company's suggestion.

\section{Third category of failures}

In the third category, failures are fixed by operators at the production point (mining room). As these are classified small failures and take little time, the mining company does not use a redundant rig.

\section{Resale value}

A declining balance depreciation model is used to estimate the resale value of our case study drilling rig after each month of operation. The rig resale value is its value if the company wants to sell it at any time during its planned lifetime. The resale value of the machine denoted $S_{i}$, is assumed to be given by the following formula $[20 ; 21]$ :

$$
S_{i}=B V_{1} \times(1-D r)^{i}
$$

where "i" represents time, $i=1,2,3, \ldots, 120$ (months), $B V_{1}$ is the rig's value on the first day of operation and $\mathrm{Dr}$ represents the depreciation rate. In addition,

$$
B V_{1}=A C \times a
$$

where " $a$ " represents the percentage that is multiplied by the rig acquisition cost to determine the rig value on the first day of use. During discussions with us, company experts agreed that the rig's purchase price decreases by $10 \%$ on the first day of use (i.e. a=0.9). In this study, the rig purchase price is $6000 \mathrm{cu}$. Hence, the rig's value on the first day of use is 5400 $c u$. The depreciation rate that allows for full depreciation by the end of the planned lifetime of the rig is modelled as follows [20]:

$$
D r=1-\left(\frac{S V}{B V_{1}}\right)^{\frac{1}{T}}
$$

where " $T$ " represents the planned lifetime of the rig, 120 months in this case study. The rig is assumed to reach scrap value (SV) after 120 months of operation.

The declining balance depreciation model is suitable in this case because it assumes that more depreciation occurs at the beginning of the equipment's planned lifetime, less at the end. It also considers the equipment is more productive when it is new, and its productivity declines continuously due to equipment degradation. Therefore, in the early years of its planned lifetime, a rig will generate more revenue than in later years. The scrap value is an estimate of the value of the equipment at the time it is disposed of. In this case study, $50 \mathrm{cu}$ is assumed to be the scrap value of the rig, following the comments of company experts.

\section{RESUTS AND DISCUSSION}

The model for $O R T$ was tested in a case study of a drilling rig. This rig is manufactured by Atlas Copco Company and used by Boliden Mineral AB in Sweden. MATLAB ${ }^{\mathrm{TM}}$ software is used to enable a variation of the replacement time $(R T)$ of (1) which minimises the total cost. The results show that the lowest possible total cost can be achieved by replacing the rig after 87 months of life. A decision to replace the rig before or after its ORT incurs greater costs for the company. Figure 1 shows the total cost versus different replacement time RTs of this case study when $C_{R_{i}}$ is equal to $3(\mathrm{cu} / \mathrm{h})$.

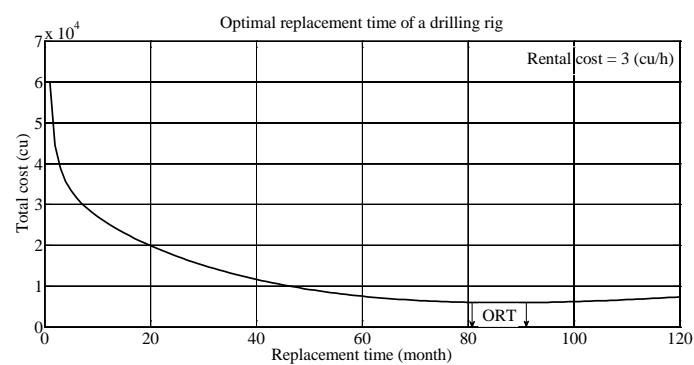

Fig. 1. Optimal replacement time of drilling rig.

Figure 1 also shows a range of 81-92 months when the minimum total cost can be still achieved in practice. In this study, we call it the optimal replacement range.

We perform sensitivity analysis to show the effect of the various cost factors influencing the rig's ORT. We look at rig acquisition, operating, maintenance and redundant rig costs using the ANN technique. We use four MATLAB codes to identify the effect of increasing acquisition cost (IAC), reduced maintenance cost $(R M C)$, reduced operating cost $(R O C)$ and reduced redundant rig cost $(R R C)$ on the ORT of a new drilling rig. The resulting ORT from these codes is fed as input to the neural network. The method of partitioning weights, proposed by Garson [22] and adopted by Goh [23], is used to determine the relative importance of these cost factors. Figure 2 illustrates 
their relative importance using a redundant rig cost per hour equal to 3 (cu/h).

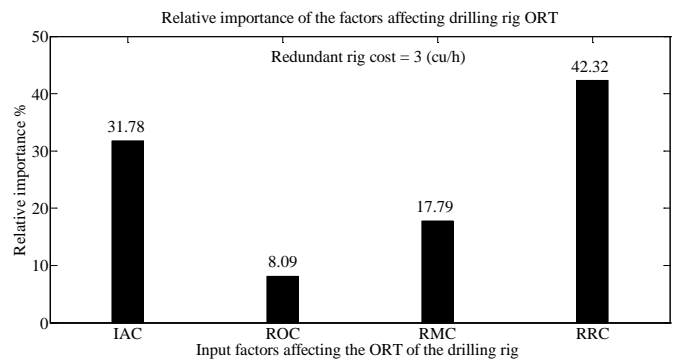

Fig. 2. Relative importance of the factors affecting the drilling rig's $O R T$

As evident in Figure 2, the most important factor influencing the $O R T$ of the drilling rig is $R R C$ followed by $I A C$, $R M C$ and $R O C$. Therefore, a design for reliability and maintainability should be adopted to reduce the downtime and maintenance costs.

To increase our understanding of the correlation between the input and output factors in the $A N N$; we performed a sensitivity analysis to identify the effect of IAC, RMC, ROC and $R R C$ on the drilling rig's $O R T$. In the sensitivity analysis, the acquisition cost increases while the $O \& M$ and redundant rig costs decrease. Figure 3 shows the $O R T$ as a function of $R R C$ with $I A C$ for a given 25\% ROC and $R M C$. Figure 4 shows the $O R T$ as a function of $R R C$ with $R M C$ for a given $25 \%$ IAC and $R O C$. Figure 5 shows the $O R T$ as a function of $R R C$ with $R O C$ for a given $25 \%$ IAC and $R M C$.

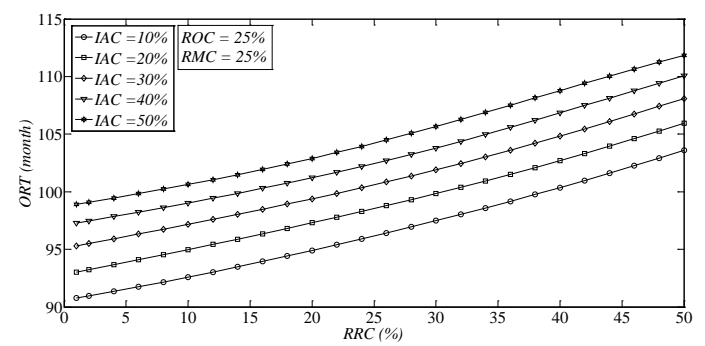

Fig. 3. ORT as a function of $R R C$ with $I A C$ for a given $25 \% R O C$ and $R M C$.

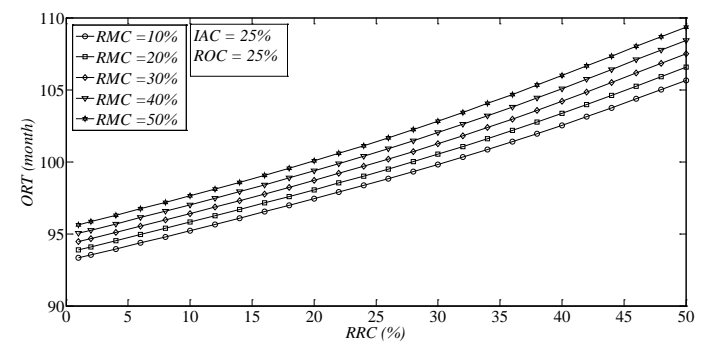

Fig. 4. ORT as a function of $R R C$ with $R M C$ for a given $25 \% I A C$ and $R O C$.

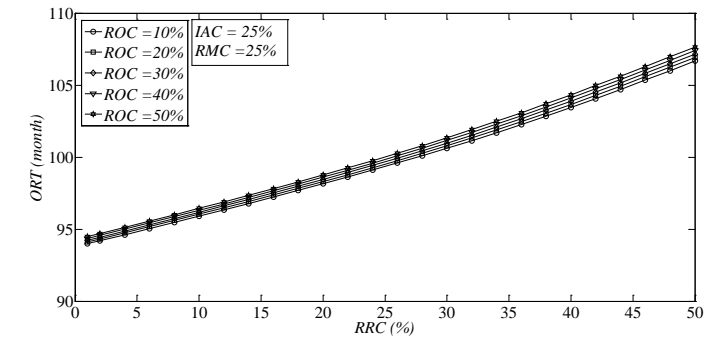

Fig. 5. ORT as a function of $R R C$ with $R O C$ for a given $25 \% I A C$ and $R M C$.

As Figures 3-5 show, RRC, IAC, RMC and ROC have a positive effect on increasing the $O R T$ of a new drilling rig. It is also evident that $R R C$ with $I A C$ has the largest impact followed by $R R C$ with $R M C$ and $R R C$ with $R O C$.

\section{A. Regression analysis}

The regression analysis of the results obtained from the four MATLAB codes uses Minitab software and the least square's method. ORT is modelled as a linear function of $I A C$, $R O C, R M C$ and $R R C$. The regression analysis results in the following mathematical model:

$$
\begin{aligned}
& O R T=85.5+0.21 \times I A C+0.02 \times R O C \\
& +0.07 \times R M C+0.27 \times R R C
\end{aligned}
$$

It is evident from the constants of the regression model (14) for this particular case (i.e. $C_{R_{i}}=3 \mathrm{cu} / \mathrm{h}$ ) that $R R C$ has largest effect on the ORT of the drilling rig followed by IAC, RMC and $R O C$. The R-squared value obtained from regression analysis, $\mathrm{R}^{2}$ (adj.) = 99.1, indicates that the ORT of the drilling rig depends linearly on the factors of $I A C, R O C, R M C$ and $R R C$. It is obvious from (14) that the regression model confirms the computations and the results of the sensitivity analysis. The mining company can use the obtained regression model to estimate the ORT of a new drilling rig. They also can use it in negotiations with manufacturing company on the purchase price of the new model, since they know the new rig's replacement time and the amount of revenue it will generate.

\section{CONCLUSIONS}

This paper presents a practical model for a finite time horizon equipment replacement problem. It is also shows the relationship between the factors affecting the ORT of a drilling rig in the particular case of using a redundant rig cost per hour equal to $3(\mathrm{cu} / \mathrm{h})$. The model is found to be a good choice for calculating the ORT of a drilling rig used in underground mines. Therefore, it can be extended to other capital assets in other industries.

According to the results of the optimisation curve, the absolute ORT of our case study is 87 months of operation. However, the ORT has a range of 81 to 92 months, during which time the total cost remains almost constant. This means the company has the flexibility to make replacements within the optimum replacement age range of 12 months.

The results of the $A N N$ analysis show that the redundant rig cost has the highest impact on the ORT. This factor affects the 
ORT of our case study by $42 \%$. The sensitivity analysis indicates that increasing the acquisition cost, decreasing the $O \& M$, and decreasing the redundant rig costs have a positive effect on increasing the ORT of a new drilling rig. This proves that improving the reliability and maintainability of rigs is essential to reduce the downtime and maintenance costs. The sensitivity analysis also shows that $R R C$ with IAC has the greatest impact on increasing the $O R T$ of a new drilling rig followed by $R R C$ with $R M C$ and $R R C$ with $R O C$. The regression analysis indicates that the $O R T$ of the new rig depends linearly on its $I A C, R O C, R M C$ and $R R C$. These results confirm the results of the sensitivity analysis.

Finally, our optimisation model can help decision makers in their management to determine when it is best economically to replace old equipment with new machines. They also can use it in negotiations with manufacturing companies on the purchase price of new drilling rigs.

\section{ACKNOWLEDGMENT}

The authors would like to thank Atlas Copco and Boliden Mineral AB for supporting this research. Special appreciation is extended to the experts at Boliden Mineral $\mathrm{AB}$ and Atlas Copco for sharing their valuable knowledge and experience to enhance our paper. The authors would like also to thank Arne Vesterberg at Boliden Mineral AB and Andreas Nordbrandt at Atlas Copco for them supports.

\section{REFERENCES}

[1] A. Jardine, and A. Tsang, Maintenance, Replacement, and Reliability Theory and Application, Taylor \& Francis Group: New York, 2006, pp.135-137.

[2] R. Bellman, "Equipment replacement policy," Journal of Society for Industrial and Applied Mathematics, vol. 3, pp. 133-136, 1955.

[3] H.M. Wagner, Principles of Operations Research, Prentice-Hall, Inc., Englewood Cliffs, 1975, pp. 303-337.

[4] R.V. Oakford, J.R. Lohmann, and A. Salazar, "Adynamic replacement economy decision model,” IIE Transactions, vol. 16, pp. 65-72, 1984.

[5] J.C. Bean, J.R. Lohmann, and R.L. Smith, "A dynamic infinite horizon replacement economy decision model," The Engineering Economist, vol. 30, pp. 99-120, 1985.

[6] J.C. Hartman, and J. Rogers, "Dynamic programming approaches for equipment replacement problems with continuous and discontinuous technological change," IMA Journal of Management Mathematics, vol. 17, pp. 143-158, 2006.
[7] N. Hritonenko, and Y. Yatsenko, "The dynamics of asset lifetime under technological change," Journal of the Operations Research Letters, vol. 36, pp. 565-568, 2008.

[8] E.J. Elton, and M.J. Gruber, "On the Optimality of an Equal Life Policy for Equipment Subject to Technological Improvement," Operational Research Quarterly, vol. 27, pp. 93-99, 1976.

[9] G. Bethuyne, "Optimal Replacement Under Variable Intensity of Utilization and Technological Progress," The Engineering Economist, vol. 43, pp. 85-105, 1998.

[10] R. Boucekkine, M. Germain, and O. Licandro, "Replacement Echoes in the Vintage Capital Growth Model,” Journal of economic theory, vol. 74, pp. 333-348, 1997.

[11] T. Cooley, J. Greenwood, and M. Yorukoglu, "The replacement problem,” Journal of Monetary Economics, vol. 40, pp. 457-499, 1997.

[12] N. Hritonenko, "Optimization Analysis of a Nonlinear Integral Model with Applications to Economics,” Nonlinear Studies, vol. 12, pp. 59-71, 2005.

[13] N. Hritonenko, and Y. Yatsenko, Applied Mathematical Modeling Of Engineering Problems, Kluwer Academic Publishers: New York, 2003, pp 183-232.

[14] J.C. Hartman, and A. Murphy, "Finite-horizon equipment replacement analysis,” IIE Transactions, vol. 38, pp. 409-419, 2006.

[15] T. Kärri, Timing of Capacity Change: Models for Capital Intensive Industry, PhD thesis, Lappeenranta University of Technology, Lappeenranta, 2007.

[16] N. Hritonenko, and Y. Yatsenko, "Integral equation of optimal replacement: Analysis and algorithms," Journal of Applied Mathematical Modelling, vol. 33, pp. 2737-2747, 2009.

[17] A. R. Wijaya, J. Lundberg, and U. Kumar, "Robust-optimum multi-attribute age-based replacement policy,” Journal of Quality in Maintenance Engineering, vol. 18, pp. 325 343, 2012.

[18] R. Dandotiya, Decision support models for the maintenance and design of mill liners, PhD thesis, Luleå University of Technology, Luleå, 2012.

[19] B. S. Blanchard, D. Verma, and E. L. Peterson, Maintainability: a key to effective serviceability and maintenance management, John Wiley \& Sons: New York, 1995, pp. 6, 426.

[20] B. Luderer, V. Nollau, and K. Vetters, Mathematical formulas for economists, $4^{\text {th }}$ ed. Springer-verlag Berlin Heidelberg: London New York, 2010, pp.43.

[21] T. Eschenbach, Engineering economy: applying theory to practice, 3rd ed., Oxford University Press: New York, 2010, pp. 173-180.

[22] G. D. Garson, "Interpreting neural network connection weights," Artificial Intelligence, vol. 6, pp. 47-51, 1991.

[23] A. T. C. Goh, "Back-Propagation neural networks for modeling complex systems,” Artificial Intelligence in Engineering, vol. 9, pp. 143-151, 1995. 